\title{
THE PHYSIOLOGIC EXPLANATION OF THE CHANGES IN THE CORONARY CIRCULATION FOLLOWING PROLONGED AORTICO-CORONARY SINUS ANASTOMOSIS ${ }^{1}$
}

\author{
By ALVIN A. BAKST, ${ }^{2,3}$ ROSARIO MANIGLIA, and CHARLES P. BAILEY \\ (From the Departments of Thoracic Surgery and Pathology, and the Brith Sholem Cardio- \\ Pulmonary Laboratory, Hahnemann Medical College and Hospital, and the Bailey \\ Thoracic Clinic, Philadelphia, Pa.)
}

(Submitted for publication September 23, 1955 ; accepted November 23, 1955)

This is a report of the physiologic changes in the coronary circulation which are precipitated by prolonged periods of arterialization of the coronary sinus.

Initial experiments pertaining to the physiology of the coronary circulation of dogs in which the coronary sinus had been arterialized for four to eight weeks demonstrated a protection to the heart against ventricular fibrillation, following sudden occlusion of the circumflex branch of the left coronary artery. In this group of animals, the myocardium was perfused in retrograde fashion with extraction of oxygen from the blood flowing backward, and the intercoronary collateral flow was increased (1-3).

Subsequently, two series of animals were studied six and twelve months respectively after arterialization of the coronary sinus, to determine whether the retroperfusion of the myocardium, and the protection to the heart against ventricular fibrillation persisted.

\section{METHODS}

Two groups of animals, whose weights varied between 15 and $18 \mathrm{~kg}$., were first prepared using the two stage operation developed by Beck (4). At a first stage, through a left-sided approach, an external jugular vein graft was placed between the aorta and the coronary sinus. Approximately one month later, using a rightsided approach, the coronary sinus was partially ligated over a probe to 2 to $3 \mathrm{~mm}$. The first group, Group A, led a normal kennel existence for six months prior to obtaining physiologic data. In the second group, Group B, physiologic data were obtained after twelve months.

1 This work was supported by the Mary Bailey Foundation.

2 This study was carried out during the tenure of a Heart Traineeship sponsored by the National Heart Institute.

3 Present Address: The Jewish Hospital of Brooklyn, 555 Prospect Place, Brooklyn 38, New York.
At this time, after the animals were anesthetized with intravenous sodium pentobarbital, artificial respiration was maintained with intermittent positive pressure, supplied through a pneophore respirator attached to an endotracheal tube with inflated rubber cuff. The left chest was entered through the fourth intercostal space, the vein graft was inspected, and only those animals in which it was patent were selected for this study. An umbilical tape was placed around the graft to facilitate its occlusion at the appropriate moment during the experiment. A needle-tipped polythene catheter attached to a water manometer was inserted into the coronary sinus, through which its pressure and a blood sample for the determination of oxygen content were obtained. The graft was occluded for two minutes, after which the data were reobtained. The circumflex branch of the left coronary artery was next dissected to its origin, and ligated. An incision was made in the wall of the artery distal to the ligature, through which it was cannulated. A sample of the circumflex coronary arterial blood flowing in retrograde fashion was collected, simultaneous samples being obtained from the aorta and the pulmonary artery, for the determination of oxygen content and saturation data. Back-flow bleeding was recorded quantitatively. The vein graft was then occluded and the same physiological measurements were made again. The peripheral segment of the circumflex coronary artery was allowed to bleed freely for two minutes during which time the retrograde flow volumes were recorded. Blood samples were then collected for determination of oxygen content. The data were collected in this order because in previous experiments, after the vein graft was occluded, the oxygen content of the back-blood emerging from the circumflex coronary artery gradually increased for two minutes before stabilizing.

\section{RESULTS}

A. Retrograde bloodflow from the peripheral segment of the ligated and transected circumflex branch of the left coronary artery

1. Group A: (Table I). With the graft open, retrograde blood flow ranged from 3.0 to $18.0 \mathrm{cc}$. per minute, with an average of $8.3 \mathrm{cc}$. per minute. Following the occlusion of the graft, the retro- 
grade circumflex arterial blood flow remained unchanged. These values ranged from 3.0 to $17.0 \mathrm{cc}$. per minute, with an average of $8.7 \mathrm{cc}$. per minute.

2. Group B: (Table II). With the graft open, the retrograde blood flow ranged from 1.0 to 12.0 cc. per minute, with an average of $6.0 \mathrm{cc}$. per minute. When the graft was occluded, the retrograde blood flow ranged from 1.0 to $12.0 \mathrm{cc}$. per minute, with an average of $6.6 \mathrm{cc}$. per minute.

Essentially, the retrograde blood flows were unchanged by the occlusion of the venous graft.

B. Oxygen content of the retrograde blood collected from the peripheral segment of the transected circumflex artery

1. Group A: (Table I). The values for the. oxygen content of this retrograde blood ranged from 10.0 to 17.4 volumes per cent, and averaged 14.6 volumes per cent. Simultaneously drawn samples of aortic blood ranged from 16.4 to 19.1 volumes per cent with an average of 17.7 volumes per cent.

2. Group B: (Table II). The oxygen content of this retrograde blood ranged from 12.9 to 18.7 volumes per cent, and averaged 16.3 volumes per cent. Concomitantly drawn samples of aortic blood ranged from 16.3 to 21.2 volumes per cent, with an average of 19.0 volumes per cent.
C. Peripheral pressure of the distal segment of the transected circumflex coronary artery

1. Group A: These values were not secured in this group.

2. Group B: (Table II). Peripheral coronary arterial pressures ranged from 16 to $40 \mathrm{~cm}$. of water, and averaged $27.5 \mathrm{~cm}$. of water.

When the aortico-coronary sinus vein graft was occluded, the pressures ranged from 16 to $55 \mathrm{~cm}$. of water, with an average of $34.5 \mathrm{~cm}$. of water.

\section{Mean coronary sinus pressure and blood oxygen content}

1. Group A : (Table I). Initially, the mean coronary sinus pressure ranged from 85 to $100 \mathrm{~cm}$. of water, and averaged $90 \mathrm{~cm}$. of water. The oxygen content of this blood ranged from 14.9 to 19.6 volumes per cent, and averaged 17.4 volumes per cent. After the aortico-coronary sinus vein graft was occluded, coronary sinus pressure rapidly fell to normal. These pressures ranged from 6.0 to $7.5 \mathrm{~cm}$. of water, and averaged $6.4 \mathrm{~cm}$. of water. The blood oxygen content now ranged from 4.8 to 10.3 volumes per cent, with an average of 8.3 volumes per cent.

2. Group B : (Table II). With the graft open, mean coronary sinus pressure ranged from 90 to

TABLE I

Arterialization of the coronary sinus for six months

Retrograde blood flow and oxygen content of blood from the peripheral segment of the ligaled and transected left circumflex coronary artery

\begin{tabular}{|c|c|c|c|c|c|c|c|c|c|}
\hline \multirow[b]{2}{*}{$\begin{array}{l}\text { Dog } \\
\text { No. }\end{array}$} & \multirow[b]{2}{*}{ Graft } & \multicolumn{2}{|c|}{ Retrograde coronary art. } & \multicolumn{2}{|c|}{ Cor. sinus } & \multicolumn{3}{|c|}{ Aortic blood } & \multirow{2}{*}{$\frac{\text { Pul. art. }}{\begin{array}{l}\mathrm{O}_{2} \text { cont. } \\
\text { Vol. \% }\end{array}}$} \\
\hline & & $\begin{array}{l}\text { Flow } \\
c c . / m i n .\end{array}$ & $\begin{array}{l}\mathrm{O}_{2} \text { cont. } \\
\text { Vol. } \%\end{array}$ & $\begin{array}{c}\text { Press. } \\
\mathrm{cm} . \mathrm{H}_{2} \mathrm{O}\end{array}$ & $\begin{array}{l}\mathrm{O}_{2} \text { cont. } \\
\text { Vol. } \%\end{array}$ & $\begin{array}{l}\text { Cont. } \\
\text { Vol. \% }\end{array}$ & $\begin{array}{c}\text { Cap }_{\dot{~}} \\
\text { Vol. } \%\end{array}$ & $\underset{\%}{\text { Sat. }}$ & \\
\hline 1 & $\begin{array}{l}\text { Open } \\
\text { Closed }\end{array}$ & $\begin{array}{l}18 \\
17\end{array}$ & $\begin{array}{l}10 \\
14.9\end{array}$ & $\begin{array}{r}85 \\
6\end{array}$ & $\begin{array}{r}16.7 \\
4.8\end{array}$ & 16.9 & 16.5 & 100 & 11.6 \\
\hline 2 & $\begin{array}{l}\text { Open } \\
\text { Closed }\end{array}$ & $\begin{array}{l}9 \\
9\end{array}$ & $\begin{array}{l}13.2 \\
18.3\end{array}$ & $\begin{array}{l}90 \\
6.5\end{array}$ & $\begin{array}{r}16.6 \\
6.0\end{array}$ & 16.9 & 16.9 & 100 & 12.4 \\
\hline 3 & $\begin{array}{l}\text { Open } \\
\text { Closed }\end{array}$ & $\begin{array}{l}4 \\
3.8\end{array}$ & $\begin{array}{l}14.8 \\
15.1\end{array}$ & $\stackrel{90}{6.5}$ & $\begin{array}{r}18.8 \\
9.8\end{array}$ & 19.1 & 19.3 & 99 & 14.8 \\
\hline 4 & $\begin{array}{l}\text { Open } \\
\text { Closed }\end{array}$ & $\begin{array}{l}7.5 \\
7.5\end{array}$ & $\begin{array}{l}17.2 \\
17.0\end{array}$ & $\begin{array}{r}85 \\
6\end{array}$ & $\begin{array}{r}19.6 \\
8.9\end{array}$ & 19.0 & 19.9 & 95.5 & 15.5 \\
\hline 5 & $\begin{array}{l}\text { Open } \\
\text { Closed }\end{array}$ & $\begin{array}{l}3 \\
3\end{array}$ & $\begin{array}{l}15.3 \\
17.2\end{array}$ & $\begin{array}{r}90 \\
6\end{array}$ & $\begin{array}{l}14.9 \\
10.3\end{array}$ & 16.4 & 17.8 & 92 & 13.5 \\
\hline 6 & $\begin{array}{l}\text { Open } \\
\text { Closed }\end{array}$ & $\begin{array}{r}8 \\
12\end{array}$ & $\begin{array}{l}17.4 \\
17.2\end{array}$ & $\begin{array}{c}100 \\
7.5\end{array}$ & $\begin{array}{r}17.9 \\
9.7\end{array}$ & 17.8 & 17.3 & 100 & 12.3 \\
\hline Av. & $\begin{array}{l}\text { Open } \\
\text { Closed }\end{array}$ & $\begin{array}{l}8.3 \\
8.7\end{array}$ & $\begin{array}{l}14.6 \\
16.6\end{array}$ & $\begin{array}{l}90 \\
6.4\end{array}$ & $\begin{array}{r}17.4 \\
8.3\end{array}$ & 17.7 & & & 13.4 \\
\hline
\end{tabular}


TABLE II

Arterialization of the coronary sinus for twelve months

Retrograde blood flow and oxygen content of blood from the peripheral segment of the ligated and transected left circumflex coronary artery

\begin{tabular}{|c|c|c|c|c|c|c|c|c|c|c|c|}
\hline \multirow[b]{2}{*}{$\begin{array}{l}\text { Dog } \\
\text { No. }\end{array}$} & \multirow[b]{2}{*}{ Graft } & \multicolumn{3}{|c|}{ Retrograde coronary artery } & \multicolumn{2}{|c|}{ Cor. sinus } & \multicolumn{4}{|c|}{ Aortic blood } & \multirow{2}{*}{$\frac{\text { Pulm. art. }}{\substack{\mathrm{O}_{2} \text { cont. } \\
\text { Vol. } \%}}$} \\
\hline & & $\underset{c c . / \text { min. }}{\text { Flow }}$ & $\begin{array}{c}\mathrm{O}_{2} \text { cont. } \\
\text { Vol. } \%\end{array}$ & $\underset{\text { Press. }}{\text { cm. } \mathrm{H}_{2} \mathrm{O}}$ & $\begin{array}{c}\text { Press. } \\
\mathrm{cm} . \mathrm{H}_{2} \mathrm{O}\end{array}$ & $\begin{array}{c}\mathrm{O}_{2} \text { cont. } \\
\text { Vol. } \%\end{array}$ & $\begin{array}{l}\text { Cont. } \\
\text { Vol. } \%\end{array}$ & $\begin{array}{l}\text { Cap. } \\
\text { Vol. } \%\end{array}$ & Sat. & $\underset{\mathrm{cm} . \mathrm{H}_{2} \mathrm{O}}{\mathrm{Pr}_{1}}$ & \\
\hline 1 & $\begin{array}{l}\text { Open } \\
\text { Closed }\end{array}$ & $\begin{array}{l}1.2 \\
1.2\end{array}$ & $\begin{array}{l}12.9 \\
16.8\end{array}$ & $\begin{array}{l}26 \\
55\end{array}$ & $\begin{array}{c}90 \\
5.6\end{array}$ & $\begin{array}{l}17.7 \\
10.1\end{array}$ & 16.3 & 16.5 & 98.8 & 95 & 10.3 \\
\hline 2 & $\begin{array}{l}\text { Open } \\
\text { Closed }\end{array}$ & $\begin{array}{r}9.0 \\
11.0\end{array}$ & $\begin{array}{l}18.7 \\
21.2\end{array}$ & $\begin{array}{l}27 \\
39\end{array}$ & $\begin{array}{r}100 \\
4.0\end{array}$ & $\begin{array}{r}19.2 \\
9.9\end{array}$ & 21.2 & 19.7 & 107.1 & 100 & 13.3 \\
\hline 3 & $\begin{array}{l}\text { Open } \\
\text { Closed }\end{array}$ & $\begin{array}{l}1.0 \\
1.0\end{array}$ & $\begin{array}{l}13.3 \\
14.6\end{array}$ & $\begin{array}{l}16 \\
16\end{array}$ & $\begin{array}{l}106 \\
4.4\end{array}$ & $\begin{array}{r}17.6 \\
1.0\end{array}$ & 19.8 & 18.5 & 107.0 & 108 & 9.0 \\
\hline 4 & $\begin{array}{l}\text { Open } \\
\text { Closed }\end{array}$ & $\begin{array}{l}7.8 \\
7.5\end{array}$ & $\begin{array}{l}18.7 \\
18.2\end{array}$ & $\begin{array}{l}40 \\
37\end{array}$ & $\begin{array}{l}110 \\
6.0\end{array}$ & 15.7 & 18.7 & 19.2 & 97.3 & 110 & 11.0 \\
\hline 5 & $\begin{array}{l}\text { Open } \\
\text { Closed }\end{array}$ & $\begin{array}{l}12.0 \\
12.0\end{array}$ & $\begin{array}{l}17.8 \\
20.6\end{array}$ & $\begin{array}{l}35 \\
33\end{array}$ & $\begin{array}{l}100 \\
5.0\end{array}$ & $\begin{array}{l}18.9 \\
11.6\end{array}$ & 20.6 & 20.4 & 100 & 100 & 13.7 \\
\hline 6 & $\begin{array}{l}\text { Open } \\
\text { Closed }\end{array}$ & $\begin{array}{l}5.0 \\
7.0\end{array}$ & $\begin{array}{l}16.4 \\
17.5\end{array}$ & $\begin{array}{l}21 \\
27\end{array}$ & $\begin{array}{r}120 \\
4.0\end{array}$ & $\begin{array}{l}17.7 \\
10.3\end{array}$ & 17.1 & 18.1 & 94.5 & 120 & 12.3 \\
\hline Av. & $\begin{array}{l}\text { Open } \\
\text { Closed }\end{array}$ & $\begin{array}{l}6.0 \\
6.6\end{array}$ & $\begin{array}{l}16.3 \\
18.1\end{array}$ & $\begin{array}{l}27.5 \\
34.5\end{array}$ & $\begin{array}{r}104 \\
4.8\end{array}$ & $\begin{array}{r}17.8 \\
7.1\end{array}$ & 19.0 & & & & 11.6 \\
\hline
\end{tabular}

$120 \mathrm{~cm}$. of water, with an average of $104 \mathrm{~cm}$. of water. The oxygen content of the arterialized coronary sinus blood ranged from 15.7 to 19.2 volumes per cent, and averaged 17.8 volumes per cent.

When the aortico-coronary sinus vein graft was clamped, the pressure within the coronary sinus rapidly fell to normal, and ranged from 4.0 to 6.0 $\mathrm{cm}$. of water with an average of $4.8 \mathrm{~cm}$. of water. The blood oxygen content now ranged from 1.0 to 11.6 volumes per cent, and averaged 7.1 volumes per cent.

\section{E. Mortality rate following circumflex coronary artery ligation}

In order to study all specimens pathologically, an arbitrary survival time of four hours subsequent to the ligation of the circumflex artery was selected as the criterion for a comparative mortality report.

1. Group A: Two dogs survived for the prescribed period of time subsequent to the ligation of the circumflex coronary artery. Four animals died of ventricular fibrillation within twenty minutes of the ligation of the circumflex artery, thus providing a mortality rate of 66 per cent.

2. Group B: Two dogs survived for the prescribed four-hour period prior to sacrifice. Four of the animals died of ventricular fibrillation within one hour of the ligation of the circumflex coronary artery, again providing for a 66 per cent mortality rate. The survivors (animals 2 and 5, Table II), demonstrated the highest rates of retrograde circumflex arterial flow. These flow rates were unchanged following the occlusion of the vein graft, which is probably indicative of the existence of an effective coronary arterial collateral circulation.

\section{F. Pathologic findings}

Since the findings that were encountered in the six and twelve-month animals were identical, both groups will be discussed together.

Vein graft: In all animals there was good union between the vein graft and the coronary sinus. The wall of the graft was thickened. There was intimal thickening, due to an increase of collagen and elastic fibers. The media and adventitia were similarly thickened, so that the two coats were indistinguishable. The intima was lined by a single layer of endothelial cells.

Coronary sinus: The changes in the wall of the coronary sinus were more pronounced. The intima was markedly thickened by large numbers of collagen and elastic fibers. This impinged upon the size of the lumen which was decreased up to approximately 50 per cent of normal. The intima was lined by a single layer of endothelial cells. In 
three dogs (animals No. 4 Table I, and No. 3 and 4 Table II) the lumen was obliterated by an acellular hyalinizing collagenous mass interpreted as an organized thrombus (Figure 1). The media and adventitia were not distinguishable because of the presence of increased bundles of interlacing collagen and elastic fibers.

Epicardial veins: The most pronounced and advanced changes were noted in the epicardial veins. The walls of these vessels demonstrated a severe degree of intimal fibroelastosis which was extensive enough to narrow the lumen critically so that no more than a slit remained in most cases (Figure 2). In many instances the lumen was replaced by a hyalinizing collagenous mass within which a few capillaries could be found. These were interpreted as being representative of recanalizing organized thrombi. The media and adventitia were not distinguishable because of the extensive fibroelastosis.

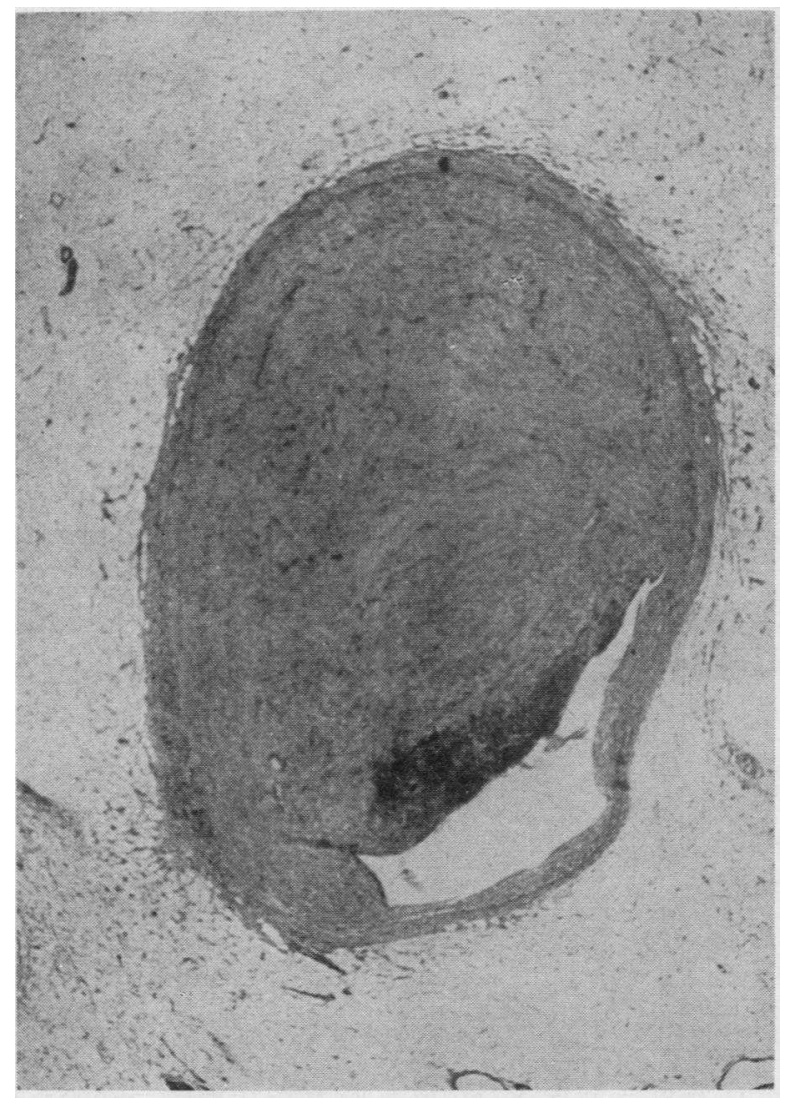

Fig. 1. Coronary Sinus

The lumen has been almost completely occluded by a large organized thrombus. $(64 \times ; H \&$ E. $)$

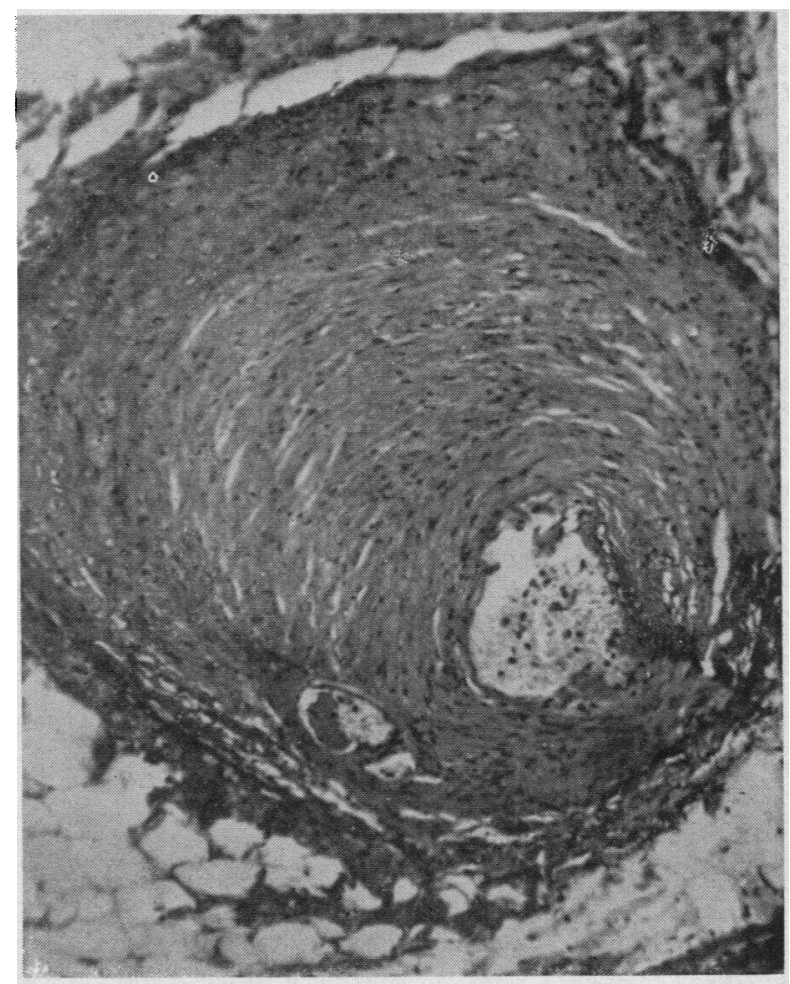

Fig. 2. Epicardial Vein Showing Pronounced Intimal Proliferation of Collagen and Elastic Fibers with Extreme Narrowing of Lumen ( $120 \times ; \mathrm{H} \& \mathrm{E}$ )

Coronary arteries: The coronary arteries examined, revealed no changes in their walls.

Myocardium: Focal areas of scarring, seen only microscopically, were found in some cases of both six and twelve-month dogs.

\section{DISCUSSION}

Since the results of this experiment are at variance with those in which the coronary sinus was arterialized for short periods of time, it might be valuable to review the preliminary results.

In a group of normal control animals, there was a small quantity of intercoronary collateral flow ( 1.7 cc. per minute). This blood was invariably arterial in nature, which demonstrated that it had originated from the neighboring coronary arteries. This backflow therefore, represented a quantitative measure of intercoronary arterial collateral flow (1). The mortality rate following circumflex arterial ligation in this group of animals was 90 per cent.

In a second group of animals in which nondescript cardiac procedures had been previously per- 
formed, the retrograde blood flow, and oxygen content of this blood, was unchanged from that of the normal control. However, in this group of animals, in which no definitive surgical procedure had been performed to increase the intercoronary collateral circulation, the mortality rate following circumflex coronary artery ligation fell to 66 per cent. It is this mortality rate that we must subsequently utilize as our baseline when evaluating the effect of any operative procedure specifically designed to increase intercoronary collateral flow.

In a third series of animals in which the coronary sinus had been arterialized for one to two months, these findings were significantly changed. With the aortico-coronary sinus vein graft open, the retrograde circumflex arterial blood flow averaged $12.2 \mathrm{cc}$. per minute, a significant increase over that of the expected normal. Moreover, this back-blood differed from that of the control animal in that it was markedly de-oxygenated, the oxygen content being within the range of normal coronary sinus blood. The desaturation of this blood was demonstrative of a retroperfusion of the myocardial capillary bed, with the ability of the myocardium to extract oxygen from this blood. When the vein graft was occluded, the retrograde circumflex coronary arterial blood flow fell to 7.1 cc. per minute, and the oxygen content reverted to normal. The arterial nature of this blood again signified that it had arisen from intercoronary anastomoses, and was suggestive of an increase in the intercoronary arterial anastomotic flow. The mortality rate in this group of animals fell to 20 per cent, which suggested a significant protection to the heart against ventricular fibrillation. This impression has been dispelled by the present series of experiments.

In the animals in which the coronary sinus was arterialized for six months, the findings were significantly changed from those previously described in the one month to two-month group. Now, with the graft functioning, the retrograde flow from the peripheral segment of the circumflex coronary artery averaged $8.3 \mathrm{cc}$. per minute. This blood was highly oxygenated, the oxygen content approximating that of the simultaneously drawn sample of aortic blood. The arterial nature of this blood indicated that it had originated from neighboring unligated arteries. When the vein graft was occluded, the backflow blood again averaged $8.7 \mathrm{cc}$. per minute, with no change in its arterial nature. Strikingly then, after six months of aortico-coronary sinus arterialization, neither the quantity nor the oxygen content of the retrograde coronary arterial blood flow was affected by the presence or absence of a functioning aortico-coronary sinus vein graft.

The investigation of the changes in the coronary circulation in animals in which coronary sinus arterialization was maintained for truly prolonged periods of time (twelve months), merely served to reconfirm those of the six-month group of animals. Apparently, the arterialized coronary sinus has completely lost contact with the myocardial capillary bed.

These findings served to confirm those recently reported by Eckstein and his associates ( 5 , 6). These workers were unable to demonstrate retroperfusion of the myocardium after three months of coronary sinus arterialization. It was suggested that blood flowing in retrograde fashion from the peripheral segment of the transected circumflex coronary artery probably originated in the anterior descending artery.

It might be well to review the comparative mortality statistics compiled during this series of physiologic experiments. Ligation of the circumflex branch of the left coronary artery in a group of normal animals resulted in a mortality rate of 90 per cent. This rate fell to 66 per cent in the group in which previous nondescript cardiac procedures had been performed. When the coronary sinus was arterialized for short periods of time, the mortality rate fell to 20 per cent. It was this impressive finding which stimulated the present investigation. These long-term experiments quickly dispelled our previous impressions. In both the six and twelve-month groups of animals there has been no protection afforded to the heart against ventricular fibrillation by the aortico-coronary sinus vein graft. The mortality rate in each group had risen to 66 per cent, which was identical to that found in the group of animals in which only nondescript cardiac procedures had been performed. This experiment has demonstrated that the initial favorable effects produced by arterialization of the coronary sinus regress over a prolonged period of time.

The inability to demonstrate any retrograde 
perfusion of the myocardial capillary bed by physiologic means has been further substantiated by the microscopic pathologic findings at the time of postmortem examination. Pathologically, there is a marked thickening of the wall of the coronary sinus, primarily due to intimal proliferation. Moreover, all of the tributaries of the coronary sinus demonstrate a severe degree of intimal proliferation. The lumina of these vessels are so markedly encroached upon by this intimal fibroelastosis, that they may be considered to be completely occluded by this process. In addition, many of the vessels are occluded by organized thrombus, which further serves to isolate the coronary sinus from the myocardial capillary bed. Apparently, prolonged periods of coronary sinus hypertension induce the production of a severe degree of intimal proliferation associated with thrombosis and organization within the small and large veins which empty into it. This intraluminal pathology serves to occlude effectively the vessels, and thereby subsequently obviate the retroperfusion of the myocardial capillary bed.

Since the initial retroperfusion of the myocardial capillary bed is negated after a period of time by the severe pathologic changes induced by the high head of pressure within the coronary sinus and its venous tributaries, it becomes apparent that in the end, the procedure does little more than transiently to increase intercoronary arterial collateral flow. It strikes us that it may be possible to attain a more lasting result by much simpler one stage procedures. We have therefore instituted a series of physiologic experiments to evaluate the simpler procedures designed to produce intraextracoronary collateral circulation.

\section{SUMMARY AND CONCLUSIONS}

1. The retrograde blood flow and oxygen content of the blood from the distal segment of a ligated circumflex artery have been determined in dogs in which the coronary sinus has been arterialized for periods of six and twelve months. These determinations have been performed with the graft open and closed.

2. With the graft open, coronary sinus pressure is within the range of that of the systemic circulation, and the coronary sinus blood is of high oxygen content.
3. When the graft is occluded, the coronary sinus pressure and blood oxygen content revert to those of normal coronary sinus levels.

4. With the graft open, retrograde circumflex coronary arterial blood flow is small in quantity but is greater than that expected in the normal control animal. This blood is arterial in nature, approximating the oxygen content of aortic blood, and is probably due to an increase in the intercoronary arterial collateral circulation.

5. Occlusion of the aortico-coronary sinus vein graft does not significantly alter these findings. This indicates that after a prolonged period of time, the aortico-coronary sinus vein graft no longer contributes to or affects the inter-arterial collateral circulation, and is therefore dispensable.

6. The mortality rate following circumflex coronary arterial ligation in both groups of animals is 66 per cent, which is unchanged from that in a series of animals in which nondescript cardiac procedures had been performed.

7. Retroperfusion of the myocardial capillary bed can no longer be demonstrated in this group of animals. Moreover, we were unable to demonstrate any protective effect upon the myocardium against ventricular fibrillation following coronary arterial occlusion in either group of animals.

\section{REFERENCES}

1. Bakst, A. A., Costas-Durieux, J., Goldberg, H., and Bailey, C. P., The physiologic explanation of the changes in the coronary circulation precipitated by aortico-coronary sinus anastomosis. J. Clin. Invest., 1954, 33, 1329.

2. Bakst, A. A., Costas-Durieux, J., Goldberg, H., and Bailey, C. P., Protection of the heart by arterialization of the coronary sinus. I. Coronary collateral flow in normal dogs and in dogs having had previous nondescript cardiac surgery. J. Thoracic Surg., 1954, 27, 433.

3. Bakst, A. A., Costas-Durieux, J., Goldberg, H., and Bailey, C. P., Protection of the heart by arterialization of the coronary sinus. II. Coronary flow in dogs with aorticocoronary sinus anastomosis. J. Thoracic Surg., 1954, 27, 442.

4. Beck, C. S., Revascularization of the heart. Ann. Surg., 1948, 128, 854.

5. Eckstein, R. W., Leighninger, D. S., Newberry, W. B., Lopez-Bellio, M., Demming, J. H., and Orbison, J. L., Studies concerning the coronary sinus anastomosis of Beck. Circulation Res., 1953, 1, 184.

6. Eckstein, R. W., and Leighninger, D. S., Chronic effects of aorta-coronary sinus anastomosis of Beck in dogs. Circulation Res., 1954, 2, 60. 